\title{
SUPERAÇÃO DA DORMÊNCIA EM SEMENTES DE FAVEIRA (Parkia platycephala Benth) ${ }^{1}$
}

\author{
Irinaldo Lima do Nascimento ${ }^{2}$, Edna Ursulino Alves ${ }^{3}$, Riselane de Lucena Alcântara Bruno ${ }^{3}$, Edilma Pereira \\ Gonçalves ${ }^{4}$, Pedro Nóbrega Quintas Colares ${ }^{2}$ e Matheus Serrano de Medeiros²
}

\begin{abstract}
RESUMO - A faveira é planta semidecídua, heliófita, que ocorre em formações secundárias e áreas abertas de terreno elevado do agreste nordestino e campinas amazônicas. A madeira dessa espécie é empregada para caixotaria, compensados, brinquedos, lenha e carvão, as vagens maduras constituem-se em excelente forragem para todos os ruminantes e a árvore é recomendada para arborização paisagística. O primeiro problema encontrado foi a baixa germinação das sementes devido à impermeabilidade do tegumento à água. Dessa forma, este trabalho teve o objetivo de determinar a metodologia mais eficiente para superação da dormência de sementes de Parkia platycephala, as quais foram submetidas a 12 tratamentos: testemunha - sementes intactas $\left(\mathrm{T}_{1}\right)$, escarificação mecânica com lixa d'água n. $80\left(\mathrm{~T}_{2}\right)$, imersão em ácido muriático concentrado $(98 \%)$ por 30 min e $1 \mathrm{~h}\left(\mathrm{~T}_{3}\right.$ e $\mathrm{T}_{4}$, respectivamente), escarificação mecânica com brita por 5,10 e $15 \mathrm{~min}\left(\mathrm{~T}_{5}, \mathrm{~T}_{6}\right.$ e $\mathrm{T}_{7}$, respectivamente) e imersão em ácido sulfúrico concentrado (98\%) por 5, 15, 30, 45 e $60 \min \left(\mathrm{T}_{8}, \mathrm{~T}_{9}, \mathrm{~T}_{10}, \mathrm{~T}_{11}\right.$ e $\mathrm{T}_{12}$, respectivamente). Os efeitos dos tratamentos foram avaliados através da porcentagem, primeira contagem e índice de velocidade de emergência de plântulas, além de comprimento e massa seca da raiz e parte aérea. Utilizou-se o delineamento inteiramente casualizado com quatro repetições, e as médias foram comparadas pelo teste de Tukey a $5 \%$ de probabilidade. Houve diferença significativa entre os tratamentos em todas as variáveis. A causa mais evidente da dormência foi a impermeabilidade do tegumento, cujos tratamentos mais eficientes para superar a dormência das sementes foram a escarificação mecânica do tegumento com lixa e a imersão em ácido sulfúrico (15 a 45 min).
\end{abstract}

Palavras-chave: Germinação, vigor e sementes florestais.

\section{DORMANCY BREAKING OF FAVEIRA (Parkia platycephala Benth.) SEEDS}

\begin{abstract}
The faveira (Parkia platycephala Benth.) is a perennial, heliophyte, secondary plant that occurs in (non-flooded) areas of the Amazon area. The wood of this species is used to make boxes, supports and toys, being of great importance for the woodworker because it is light and easily laminated, characteristics that have increased the interest in using it in reforestation programs. The seeds have low germination due to the impermeability of the tegument to water. This study determined the most efficient methodology for dormancy breaking in Parkia platycephala. The seeds were submitted to 12 treatments: control - intact seeds $\left(T_{1}\right)$, mechanical scarification with no.. 80 sandpaper $\left(T_{2}\right)$, immersion in concentrated muriatic acid $(98 \%)$ for 30 minutes and one hour ( $T_{3}$ and $T_{4}$, respectively), mechanical scarification with gravel for 5,10 and 15 minutes $\left(T_{5}, T_{6}\right.$ and $T_{7}$, respectively) and immersion in concentrated sulfuric acid (98\%) for 5, 15, 30, 45 and 60 minutes $\left(T_{8}, T_{9}, T_{10}, T_{11}\right.$ and $T_{1} 2$, respectively). The effects of the treatments were assessed through germination percentage and first count, seedling emergence velocity index and length and dry mass of the root and aerial leaves. A completely randomized design was used with four repetitions. The averages were
\end{abstract}

\footnotetext{
${ }^{1}$ Recebido em 18.09.2007 e aceito para publicação em 26.01.2009.

${ }^{2}$ Graduação em Agronia da Universidade Federal da Paraíba (UFPB). E-mail: <iririlima@ hotmail.com>.

${ }_{3}^{3}$ Departamento de Fitotecnia da UFPB, Areia-PB.E-mail : <ednaursulino@cca.ufpb.br>e <lane@cca.ufpb.br>.

${ }^{4}$ Departamento de Agronomia daUniversidade Federal Rural de Pernambuco (UFRPE). E-mail: <edilmapg@ hotmail.com>.
} 
compared by the Tukey test at 5\% probability. There was a significant difference among the treatments for all the variables. Tegument impermeability is the most evident cause of dormancy. The most efficient treatments to overcome seed dormancy were mechanical scarification of the tegument with sandpaper and sulfuric acid immersion (15 to 45 minutes).

Keywords: germination, vigor and forest seeds.

\section{INTRODUÇÃO}

O gênero Parkia, subfamília Mimosoideae, é encontrado principalmente em floresta tropical úmida, onde existem aproximadamente 17 espécies que ocorrem em áreas de floresta de terra firme, várzea sazonal e floresta secundária (HOPKINS, 1986). Dessas espécies, P. multijuga Benth., P. nitida Miquel, P. paraensis Ducke, P. ulei (Harms) Kuhlm. e P. platycephala Benth. são conhecidas como fornecedoras de madeiras comerciais na Amazônia (IBDF, 1987).

Parkia platycephala, conhecida popularmente como faveira, faveira-de-bolota, fava-de-bolota, visgueiro, fava-de-boi e sabiú, entre outros, ocorre na Região Nordeste do país, transição do Cerrado ou da mata Atlântica para a Caatinga, em regiões elevadas de até $900 \mathrm{~m}$ de altitude e também nas campinas da região Amazônica (LORENZI, 2002). Esse autor enfatizou ainda que a espécie tem potencial paisagístico, forrageiro, cujas vagens maduras constituem excelente fonte de suplementação alimentar para todos os ruminantes, além de a madeira ser utilizada para caixotaria, tabuados para divisões internas em pequenas construções, forros, confecção de brinquedos, bem como para lenha e carvão. Alves et al. (2007) também enfatizaram a importância do uso das vagens da referida espécie na suplementação alimentar de ruminantes.

Um dos fatores que dificultam a propagação da Parkia platycephala é o alto grau de dormência das sementes, impedindo a sua germinação. A dormência é o fenômeno pelo qual sementes de determinada espécie, mesmo sendo viáveis e tendo todas as condições ambientais favoráveis à germinação, deixam de germinar. Na natureza é um recurso usado pelas plantas produtoras de sementes para perpetuação de suas espécies, uma vez que o fenômeno da dormência impede que todas as sementes germinem na mesma época, aumentando sua chance de sobrevivência e diminuindo o risco de extinção da espécie (CARVALHO e NAKAGAWA, 2000). Segundo Yap e Wong (1983), isso pode ocorrer devido à impermeabilidade do tegumento à água, fenômeno considerado como uma das causas mais comuns da dormência nas leguminosas e em algumas espécies das famílias Malvaceae, Chenopodiaceae, Convolvulaceae, Liliaceae e Solanaceae (POPINIGIS, 1985; CARVALHO e NAKAGAWA, 2000).

Quanto aos tipos de dormência, Bewley e Black (1994) reconheceram três: imposta pelo tegumento, imaturidade do embrião e substâncias promotoras e inibidoras da germinação. A impermeabilidade do tegumento pode ser determinada pela deposição de substâncias como suberina, lignina, cutina e mucilagens, na testa, pericarpo ou membrana nuclear, sendo este o mecanismo de dormência mais comum entre as espécies da família Leguminosae (MAYER e POLJAKOFFMAYBER, 1982; BEWLEY e BLACK, 1985). Entre as várias causas de dormência, Villiers (1972) ressaltou que a impermeabilidade do tegumento à água é um tipo bastante comum em sementes da família Leguminosae, enquanto Rolston (1978) enfatizou que, de 260 espécies de leguminosas examinadas, cerca de $85 \%$ apresentavam sementes com tegumento total ou parcialmente impermeável à água.

A dormência das sementes de leguminosas é uma característica hereditária, atribuída à camada de células em paliçada, cujas paredes celulares são espessas e recobertas externamente por uma camada cuticular cerosa. Em condições naturais, essa impermeabilidade se reduz gradualmente, de modo que certa proporção de sementes germina a cada período. Entretanto, em laboratório, a ruptura do tegumento permite a imediata embebição e o início do processo germinativo (FERNANDEZ et al., 2000). Dessa forma, a imersão em água quente por alguns minutos, a escarificação com lixa e a escarificação química com ácido sulfúrico têm sido utilizadas, de forma bem sucedida, para eliminar a dormência nos tegumentos das sementes de leguminosas (PEREZ, 2004).

Embora seja um mecanismo eficiente para garantir a sobrevivência e perpetuação da espécie, a dormência 
se constitui num fator limitante à sua propagação, tendo em vista que apenas pequena porcentagem das sementes germina em condições naturais. Entre os tratamentos utilizados com sucesso para superação da dormência tegumentar de espécies florestais, destacam-se as escarificações (mecânica e química), além da imersão das sementes em água quente. A aplicação e eficiência desses tratamentos dependem do grau de dormência, que é variável entre diferentes espécies, procedências e anos de coleta (OLIVEIRA et al., 2003).

A escarificação mecânica através do atrito das sementes contra superfícies abrasivas vem sendo recomendada, para pequenos lotes de sementes, com bons resultados em sementes de Adesmia muricata (Jacq.) DC. e Trifolium resupinatum L. (MEDEIROS e NABINGER, 1996), Peltophorum dubium Sprenger Taubert (PEREZ et al., 1999), Bauhinia monandra Britt. (ALVES et al., 2000), Dimorphandra mollis Benth. (HERMANSEN et al., 2000), Acacia mearnsii Willd. (ROVERSI et al., 2002), Operculina macrocarpa (L.) Farwel (MEDEIROS FILHO et al., 2002), Ormosia arborea (Vell.) Harms. (LOPES et al., 2004), Bauhinia divaricata L. (ALVES et al., 2004), Acacia mangium Willd. (SMIDERLE et al., 2005), Ormosia nitida Vog (LOPES et al., 2006), Leucaena leucocephala (Lam.) De Wit. (DEMINICIS et al., 2006), entre outras.

O tratamento com ácido sulfúrico tem sido utilizado, com sucesso, na superação da dormência de sementes de Trema micrantha (L.) Blume (CASTELLANI e AGUIAR, 1997), Parkia multijuga Benth. (BIANCHETTI et al., 1998), Cassia excelsa Schrad (JELLER e PEREZ, 1999), Guazuma ulmifolia Lam. (ARAUJO-NETO e AGUIAR, 2000), Ochroma lagopus Sw. (BARBOSA et al., 2004), Tachigalia multijuga Benth. (BORGES et al., 2004), Ormosia arborea (LOPES et al., 2004) e de Zizyphus joazeiro Mart. (ALVES et al., 2006). Observou-se, ainda, que o sucesso do tratamento está relacionado com o tempo de exposição ao ácido e à espécie.

A escarificação química de sementes de Leucaena leucocephala com ácido sulfúrico durante 15 ou 20 min resultou em porcentagem de germinação acima de 90\% (TELES et al., 2000). Sementes de Dimorphandra mollis submetidas à escarificação com ácido sulfúrico por períodos entre 45 e 90 min apresentaram porcentagem de germinação superior a 90\% (HERMANSEN et al., 2000). De acordo com Boscagli e Sette (2001), a escarificação de sementes de Satureja montana L. com ácido sulfúrico não foi efetiva em aumentar a germinação quando aplicada por $60 \mathrm{seg}$, no entanto, por mais que cinco min, tornou-se prejudicial. Sreerama et al. (2000) obtiveram as maiores porcentagens de germinação de sementes de Delonix regia Raf. e Cassia fistula L. quando estas foram submetidas a tratamentos com ácido sulfúrico por 15 e $30 \mathrm{~min}$, respectivamente. Em Enterolobium contortisiliquum (Vell.) Morong., segundo Meneghello et al. (2000), o tratamento com ácido sulfúrico por 10 min resultou no aumento da porcentagem de germinação, melhoria na uniformidade de emergência das mudas e maior comprimento de raízes.

Com isso, tem-se a necessidade de testar métodos práticos de superação da dormência que melhorem a germinação e o desempenho de mudas no viveiro, para acelerar e uniformizar o estabelecimento inicial de plantas no campo. Dessa forma, o trabalho teve por objetivo determinar tratamentos pré-germinativos eficientes para aumentar e uniformizar a germinação de sementes de Parkia platycephala.

\section{MATERIAL E MÉTODOS}

O trabalho foi realizado em casa de vegetação do Departamento de Fitotecnia do Centro de Ciências Agrárias da Universidade Federal da Paraíba, em Areia, PB (658'12''S e 35 42'15' W), em dezembro de 2006. Foram utilizadas sementes de Parkia platycephala colhidas manualmente, diretamente de árvores matriz localizadas no campus universitário, no Município de Areia, PB.

As sementes foram submetidas aos seguintes tratamentos: testemunha $\left(\mathbf{T}_{1}\right)$ - sementes intactas; escarificação mecânica com lixa d'água n. $80\left(\mathbf{T}_{2}\right)$ - as sementes foram friccionadas manualmente em lixa d'água n. 80 até o desgaste visível do tegumento no lado oposto à micrópila; imersão em ácido muriático concentrado (98\%) por $30 \mathrm{~min}$ e $1 \mathrm{~h}\left(\mathrm{~T}_{3}\right.$ e $T_{4}$, respectivamente) - consistiu na imersão das sementes em ácido muriático concentrado, nos períodos predeterminados, e, decorridos esse tempo, foram retiradas e lavadas em água corrente por $10 \mathrm{~min}$; escarificação mecânica com brita por 5,10 e $15 \min \left(T_{5}, T_{6}\right.$ e $T_{7}$, respectivamente) - as sementes, juntamente com a brita, foram colocadas em recipientes e submetidas à agitação pelos períodos descritos anteriormente;

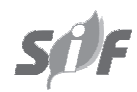

R. Árvore, Viçosa-MG, v.33, n.1, p.35-45, 2009 
imersão em ácido sulfúrico concentrado $(98 \%)$ por $5,15,30,45$ e $60 \min \left(T_{8}, T_{9}\right.$, $\mathbf{T}_{10}, \mathbf{T}_{11}$ e $\mathbf{T}_{12}$, respectivamente), realizado mediante a imersão das sementes no ácido concentrado, pelos períodos citados anteriormente, após o que foram lavadas em água corrente por $10 \mathrm{~min}$. O ácido muriático foi utilizado porque a probabilidade de acidentes é menor do que com o ácido sulfúrico; assim, pretendia-se disponibilizar uma forma mais segura de superação da dormência.

Depois de submetidas aos tratamentos, as sementes foram semeadas em bandejas plásticas perfuradas no fundo, contendo areia lavada, previamente peneirada e esterilizada em autoclave, umedecida com quantidade de água equivalente a $60 \%$ da capacidade de retenção, cuja manutenção da umidade foi por meio de irrigações diárias. Avaliaram-se as seguintes características:

Emergência - Foram utilizadas 100 sementes por tratamento, divididas em quatro sub-amostras de 25. As contagens do número de plântulas emergidas iniciaram-se aos três e estenderam-se até os 22 dias após a semeadura, utilizando-se como critério as plântulas normais que apresentavam os cotilédones acima do nível do substrato (BRASIL, 1992). Os resultados foram expressos em porcentagem; primeira contagem de emergência - correspondente à porcentagem acumulada de plântulas normais no sexto dia após o início do teste; índice de velocidade de emergência (IVE) - foram realizadas contagens diárias, dos três aos 22 dias, das plântulas normais, sendo o índice calculado conforme a fórmula proposta por Maguire (1962); comprimento de plântulas - no final do teste de emergência, as plântulas normais de cada repetição foram medidas com o auxílio de uma régua graduada em centímetros, sendo os resultados expressos em centímetros por plântula; massa seca das plântulas - após a contagem final no teste de emergência, as plântulas foram secas em estufa regulada a $80^{\circ} \mathrm{C}$ por $24 \mathrm{~h}$ e, decorrido esse período, pesadas em balança analítica com precisão de $0,001 \mathrm{~g}$, conforme recomendações de Nakagawa (1999).

O delineamento experimental utilizado foi o inteiramente casualizado, constando de 12 tratamentos. Os dados, sem transformações, foram submetidos à análise de variância, sendo a comparação entre as médias feita pelo teste de Tukey a 5\% de probabilidade, quando houve significância no teste $\mathrm{F}$, em que se utilizou o software ESTAT, versão 2.0/2001.

\section{RESULTADOS E DISCUSSÃO}

De acordo com os dados da Figura 1, observase que as maiores porcentagens de emergência de plântulas ocorreram quando as sementes foram submetidas aos tratamentos de escarificação manual com lixa $\left(\mathrm{T}_{1}\right)$ e imersão em ácido sulfúrico concentrado por 15, 30 e $45 \min \left(\mathrm{T}_{9}, \mathrm{~T}_{10}\right.$ e $\mathrm{T}_{11}$, respectivamente), os quais não diferiram estatisticamente do tratamento de imersão em ácido sulfúrico por $5 \mathrm{~min}\left(\mathrm{~T}_{8}\right)$. Os demais tratamentos não se mostraram eficientes em promover uma emergência de plântulas rápida e uniforme, provavelmente por terem provocado danos às sementes ou não terem conseguido romper a camada responsável pela impermeabilização. A superação da dormência das sementes de $P$. platycephala com os tratamentos de escarificação mecânica com lixa e química com ácido sulfúrico deveu-se ao fato de eles terem provocado algum tipo de ruptura no tegumento, de forma a não comprometer a sua qualidade fisiológica. Nesse sentido, Medeiros Filho et al. (2002) relataram que a escarificação mecânica provoca fissuras no tegumento, aumentando a permeabilidade e permitindo a embebição e, consequentemente, o início da germinação. Em espécies do gênero Parkia, sementes tratadas com ácido sulfúrico e escarificação manual no tegumento geralmente apresentam índices elevados de germinação (VARELA et al., 1986/1987; CRUZ et al., 2001).

Em vários trabalhos, a escarificação mecânica foi empregada, com sucesso, na superação da dormência das sementes de Tetrapleura tetraptera Schum \& Thonn (ODOEMENA, 1988), Bauhinia racemosa Lam. (PRASAD e NAUTIYAL, 1996), Enterolobium contortisiliquum e Tapura amazonica Poep. \& Endl. (MONTEIRO e RAMOS, 1997), Cassia grandis L. e Samanea saman Merrill (LOPES et al., 1998), Leucaena diversifolia (Schlecht.) Bentham K156 (BERTALOT e NAKAGAWA, 1998), Dimorphandra mollis (HERMANSEN et al., 2000), Bauhinia ungulata L. (ALVES et al., 2000), Operculina macrocarpa (MEDEIROS FILHO et al., 2002), Bauhinia divaricata (ALVES et al., 2004), Ormosia arborea (LOPES et al., 2004) e de Ormosia nitida (LOPES et al., 2006) e de Trifolium riograndense Burkart (SUÑÉ e FRANKE, 2006).

Em sementes com tegumento impermeável, tratamentos feitos com a utilização de ácido sulfúrico têm revelado bons resultados na superação desse tipo de dormência, conforme relatado por Bewley e Black 
(1994) e verificado em sementes de Senna macranthera (ESCHIAPATI-FERREIRA e PEREZ 1997), Caesalpinea ferrea, Cassia grandis e Samanea saman (LOPES et al., 1998), Mimosa caesalpiniaefolia Benth. (BRUNO et al., 2001; GARCIA et al., 2002), Bowdichia virgilioides Kunth. (SMIDERLEe SOUZA, 2003), Bauhinia monandra (ALVES et al., 2004) e de Ormosia arborea (LOPES et al., 2004).

A exemplo do que ocorreu com a porcentagem de emergência, os tratamentos de escarificação manual com lixa $\left(\mathrm{T}_{1}\right)$ e imersão em ácido sulfúrico concentrado por 15,30 e $45 \min \left(\mathrm{T}_{9}, \mathrm{~T}_{10}\right.$ e $\mathrm{T}_{11}$, respectivamente) foram responsáveis pelas maiores porcentagens de emergência de plântulas por ocasião da primeira contagem (Figura 2). Esses resultados indicaram que a escarificação mecânica e o ácido sulfúrico foram mais eficazes em romper o tegumento das sementes de Parkia platycephala. Assim, a água foi absorvida pelas sementes, embebendo-as, o que desencadeou, de forma rápida e uniforme, o processo de germinação e posterior emergência das plântulas. Mais uma vez, observouse que os outros tratamentos não foram eficazes na superação da dormência das sementes.

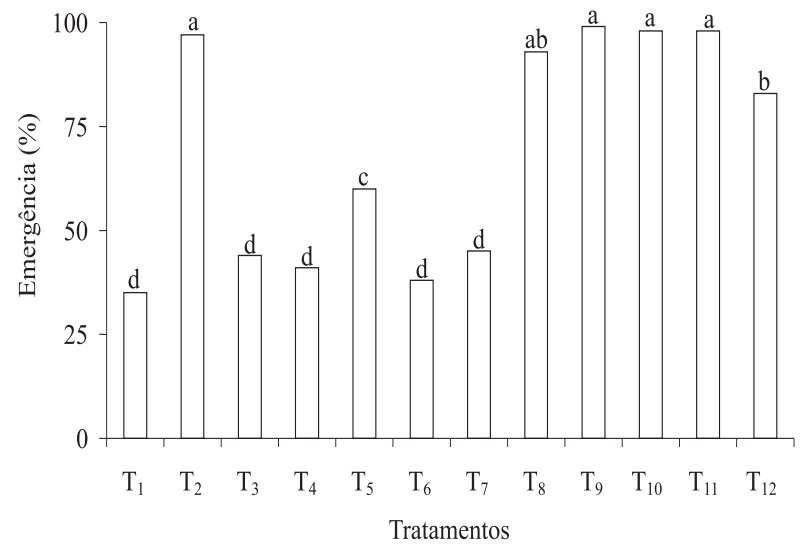

Médias seguidas de mesma letra não diferem estatisticamente, pelo teste de Tukey a $5 \%$.

Testemunha $\left(\mathrm{T}_{1}\right)$ - sementes intactas; escarificação mecânica com lixa d'água n. $80\left(\mathrm{~T}_{2}\right)$; imersão em ácido muriático concentrado $(98 \%)$ por 30 min e $1 \mathrm{~h}$ ( $\mathrm{T}_{3}$ e $\mathrm{T}_{4}$, respectivamente); escarificação mecânica com brita por 5,10 e $15 \min \left(\mathrm{T}_{5}, \mathrm{~T}_{6}\right.$ e $\mathrm{T}_{7}$, respectivamente); e imersão em ácido sulfúrico concentrado $(98 \%)$ por $5,15,30,45$ e $60 \mathrm{~min}$ $\left(\mathrm{T}_{8}, \mathrm{~T}_{9}, \mathrm{~T}_{10}, \mathrm{~T}_{11}\right.$ e $\mathrm{T}_{12}$, respectivamente).

Figura 1 - Emergência de plântulas de Parkia platycephala oriundas de sementes submetidas a diferentes tratamentos pré-germinativos.

Figure 1-Emergence of Parkia platycephala seedlings originated from seeds submitted to different pre-germination treatments.

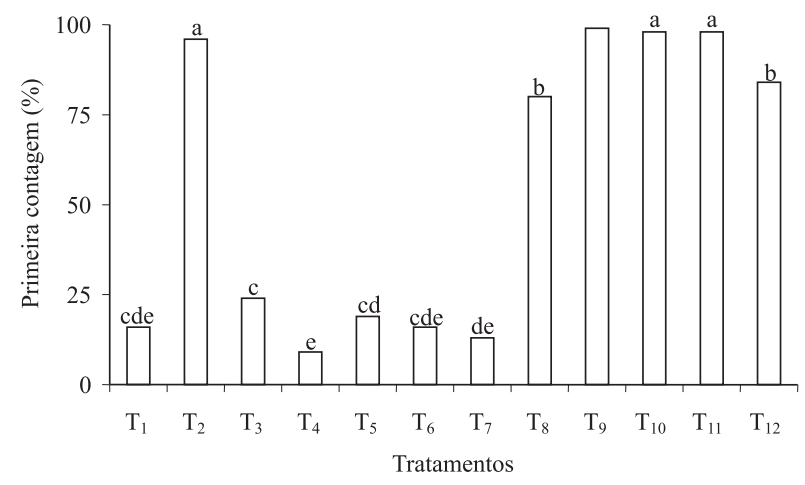

Médias seguidas de mesma letra não diferem estatisticamente, pelo teste de Tukey a $5 \%$.

Testemunha $\left(T_{1}\right)$ - sementes intactas; escarificação mecânica com lixa d'água n. $80\left(\mathrm{~T}_{2}\right)$; imersão em ácido muriático concentrado $(98 \%)$ por $30 \mathrm{~min}$ e $1 \mathrm{~h}\left(\mathrm{~T}_{3}\right.$ e $\mathrm{T}_{4}$, respectivamente); escarificação mecânica com brita por $5,10 \mathrm{e} 15 \mathrm{~min}\left(\mathrm{~T}_{5}, \mathrm{~T}_{6} \mathrm{e} \mathrm{T}_{7}\right.$, respectivamente); e imersão em ácido sulfúrico concentrado $(98 \%)$ por $5,15,30,45$ e $60 \mathrm{~min}$ $\left(\mathrm{T}_{8}, \mathrm{~T}_{9}, \mathrm{~T}_{10}, \mathrm{~T}_{11}\right.$ e $\mathrm{T}_{12}$, respectivamente $)$.

Figura 2 - Primeira contagem de emergência de plântulas de Parkia platycephala oriundas de sementes submetidas a diferentes tratamentos prégerminativos.

Figure 2 - First count of emergence of Parkia platycephala seedlings originated from seeds submitted to different pre-germination treatments.

Em Acacia mearnsii, Roversi et al. (2002) obtiveram as maiores porcentagens de germinação, por ocasião da primeira contagem, quando submeteram as sementes à escarificação mecânica por $15 \mathrm{seg}$. De forma semelhante, o mais alto vigor (primeira contagem de emergência) de sementes de Bauhinia divaricata ocorreu quando se utilizou o desponte na região oposta à micrópila e escarificação com lixa n. 80 (ALVES et al., 2004).

As sementes de Sterculia foetida L. também apresentaram as maiores porcentagens de germinação, na primeira contagem, quando foram escarificadas nos dois lados, sem embebição, seguidas por aquelas submetidas à escarificação mecânica em um lado com embebição (SANTOS et al., 2004).

Para Zizyphus joazeiro, Alves et al. (2006) observaram que o pré-condicionamento das unidades de dispersão em ácido sulfúrico concentrado mostrou-se eficiente, pois promoveu aumento no vigor determinado pela primeira contagem de emergência. No entanto, os autores comentaram que a eficiência do tratamento químico com ácido sulfúrico concentrado depende do período de imersão, sendo a faixa entre 74 e $115 \mathrm{~min}$ mais adequada para proporcionar maior vigor.

R. Árvore, Viçosa-MG, v.33, n.1, p.35-45, 2009 
Quanto ao vigor determinado pelo índice de velocidade de emergência (Figura 3), observou-se que o mais elevado valor foi obtido com sementes submetidas aos tratamentos de escarificação manual com lixa $\left(\mathrm{T}_{1}\right)$ e imersão em ácido sulfúrico concentrado por 15, 30 e $45 \min \left(\mathrm{T}_{9}, \mathrm{~T}_{10}\right.$ e $\mathrm{T}_{11}$, respectivamente). Mais uma vez, constatou-se a eficiência desses tratamentos em superar a dormência das sementes, de forma que estas puderam expressar o seu máximo potencial fisiológico. Frank e Baseggio (1998) relataram que apesar de a escarificação mecânica provocar fissuras no tegumento das sementes, ela aumenta a sua permeabilidade, permitindo a embebição e aceleração do início do processo de germinação. Resultados semelhantes foram obtidos por Roversi et al. (2002) com Acacia mearnsii, em que os maiores valores de velocidade de germinação ocorreram quando as sementes foram submetidas à escarificação mecânica por $15 \mathrm{seg}$.

Os maiores valores do índice de velocidade de emergência de plântulas de Bauhinia divaricata ocorreram com as sementes submetidas ao desponte na região oposta à micrópila e escarificação com lixa n. 80 (ALVES et al., 2004). Para Ormosia arborea, a escarificação mecânica e a escarificação química durante 10,20 e 30 min reduziram a dormência e aumentaram significativamente a velocidade de germinação das sementes (LOPES et al., 2004). Os tratamentos de escarificação mecânica e ácido sulfúrico também reduziram a dormência e aumentaram a velocidade de germinação das sementes de Ormosia nitida (LOPES et al., 2006).

A escarificação manual com lixa proporcionou os melhores resultados para o índice de velocidade de emergência das plântulas de Leucaena leucocephala (DEMINICIS et al., 2006), enquanto em Zizyphus joazeiro Alves et al. (2006) constataram que o précondicionamento das unidades de dispersão em ácido sulfúrico concentrado mostrou-se eficiente, pois promoveu aumento no vigor determinado pelo índice de velocidade de emergência.

Quanto ao comprimento da raiz principal, verificouse a superioridade do desempenho das sementes escarificadas com lixa $\left(\mathrm{T}_{2}\right)$ e daquelas tratadas com ácido sulfúrico durante 45 min $\left(\mathrm{T}_{11}\right)$, no entanto não houve diferença estatística das sementes da testemunha $\left(\mathrm{T}_{1}\right.$ ) (Figura 4), em relação aos outros tratamentos, uma vez que se obtiveram os maiores valores. Os melhores resultados de comprimentos da parte aérea (Figura 5) também foram constatados com a escarificação mecânica com lixa $\left(\mathrm{T}_{2}\right)$ e imersão em ácido sulfúrico por 5, 15, 30,45 e 60 min $\left(T_{8}, T_{9}, T_{10}, T_{11}\right.$ e $T_{12}$, respectivamente). Esses resultados se devem, provavelmente, a um menor consumo das reservas das sementes durante o processo germinativo, uma vez que ela ocorreu de forma rápida e uniforme. Assim, essas reservas foram destinadas ao crescimento das plântulas resultantes. Resultados diferentes foram obtidos por Sampaio et al. (2001), quando observaram redução no crescimento de plântulas de Bowdichia virgilioides com a imersão das sementes em ácido sulfúrico concentrado por períodos superiores a 2 min.

Em Acacia mearnsii, a escarificação mecânica por 15 seg também foi responsável pelos maiores valores de comprimento da raiz das plântulas (ROVERSI et al., 2002). Alves et al. (2006) observaram que o pré-condicionamento das unidades de dispersão de Zizyphus joazeiro em ácido sulfúrico concentrado mostrou-se eficiente, pois promoveu aumento na altura das plantas.

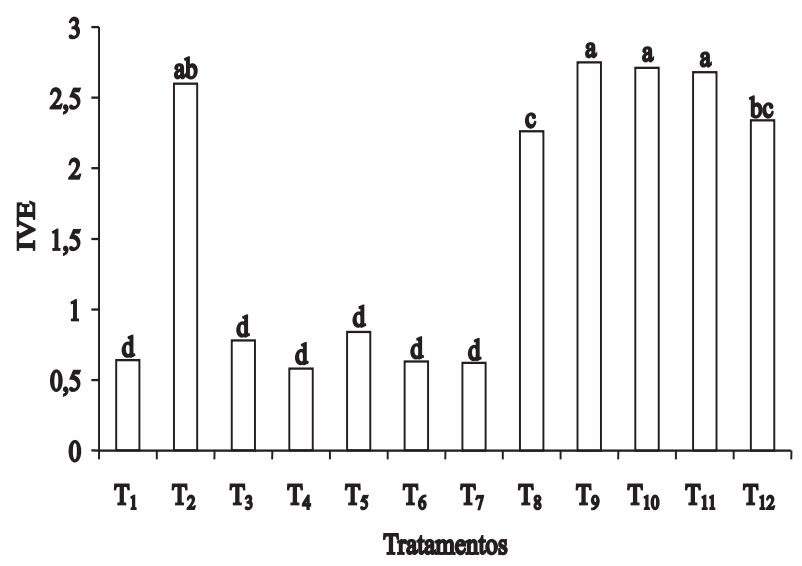

Médias seguidas de mesma letra não diferem estatisticamente, pelo teste de Tukey a $5 \%$.

Testemunha $\left(\mathrm{T}_{1}\right)$ - sementes intactas; escarificação mecânica com lixa d'água n. 80 ( $\left.\mathrm{T}_{2}\right)$; imersão em ácido muriático concentrado $(98 \%)$ por 30 min e $1 \mathrm{~h}\left(\mathrm{~T}_{3}\right.$ e $\mathrm{T}_{4}$, respectivamente); escarificação mecânica com brita por 5,10 e $15 \mathrm{~min}\left(\mathrm{~T}_{5}, \mathrm{~T}_{6}\right.$ e $\mathrm{T}_{7}$, respectivamente); e imersão em ácido sulfúrico concentrado $(98 \%)$ por $5,15,30,45$ e $60 \mathrm{~min}$ $\left(\mathrm{T}_{8}, \mathrm{~T}_{9}, \mathrm{~T}_{10}, \mathrm{~T}_{11}\right.$ e $\mathrm{T}_{12}$, respectivamente).

Figura 3 - Índice de velocidade de emergência de plântulas de Parkia platycephala oriundas de sementes submetidas a diferentes tratamentos prégerminativos.

Figure 3 - Emergence velocity index of Parkia platycephala seedlings originated from seeds submitted to different pre-germination treatments. 


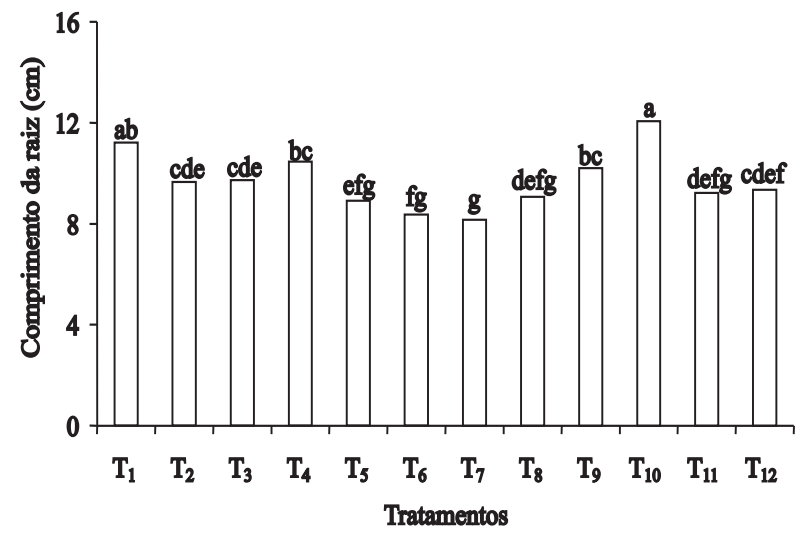

Médias seguidas de mesma letra não diferem estatisticamente, pelo teste de Tukey a 5\%. Testemunha $\left(\mathrm{T}_{\text {, }}\right)$ - sementes intactas; escarificação mecânica com lixa d'água n. $80\left(\mathrm{~T}_{2}\right)$; imersão em ácido muriático concentrado $(98 \%)$ por $30 \mathrm{~min} \mathrm{e} 1 \mathrm{~h}\left(\mathrm{~T}_{3}\right.$ e $\mathrm{T}_{4}$, respectivamente); escarificação mecânica com brita por 5,10 e $15 \min \left(\mathrm{T}_{5}, \mathrm{~T}_{6}\right.$ e $\mathrm{T}_{7}$, respectivamente); e imersão em ácido sulfúrico concentrado (98\%) por 5, 15, 30, 45 e $60 \min \left(\mathrm{T}_{8}, \mathrm{~T}_{9}, \mathrm{~T}_{10}, \mathrm{~T}_{11}\right.$ e $\mathrm{T}_{12}$, respectivamente).

Figura 4 - Comprimento da raiz principal de plântulas de Parkia platycephala oriundas de sementes submetidas a diferentes tratamentos pré-germinativos.

Figure 4-Primary root length of Parkia platycephala seedlings originated from seeds submitted to different pregermination treatments.

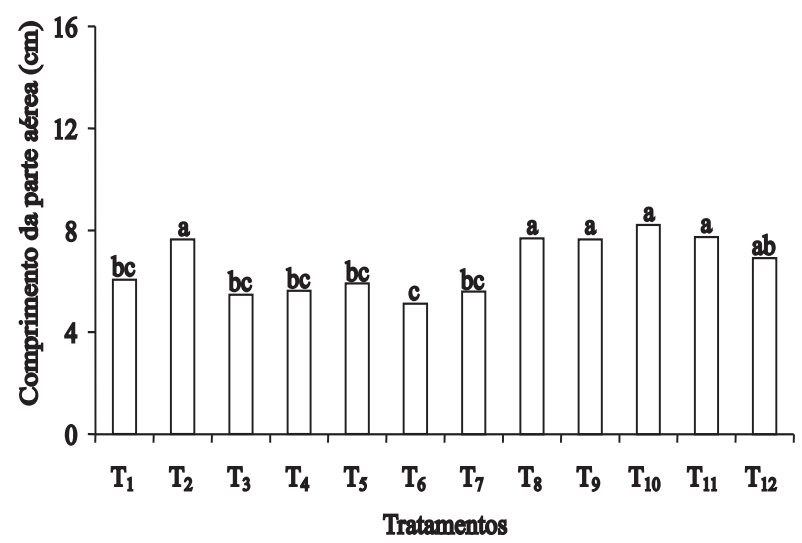

Médias seguidas de mesma letra não diferem estatisticamente, pelo teste de Tukey a $5 \%$.

Testemunha $\left(\mathrm{T}_{1}\right)$ - sementes intactas; escarificação mecânica com lixa d'água n. 80 ( $\left.\mathrm{T}_{2}\right)$; imersão em ácido muriático concentrado $(98 \%)$ por 30 min e $1 \mathrm{~h}\left(\mathrm{~T}_{3}^{2}\right.$ e $\mathrm{T}_{4}$, respectivamente); escarificação mecânica com brita por 5,10 e 15 min $\left(\mathrm{T}_{5}, \mathrm{~T}_{6}\right.$ e $\mathrm{T}_{7}$, respectivamente); e imersão em ácido sulfúrico concentrado $(98 \%)$ por $5,15,30,45$ e $60 \mathrm{~min}$ $\left(\mathrm{T}_{8}, \mathrm{~T}_{9}, \mathrm{~T}_{10}, \mathrm{~T}_{11}\right.$ e $\mathrm{T}_{12}$, respectivamente).

Figura 5 - Comprimento da parte aérea de plântulas de Parkia platycephala oriundas de sementes submetidas a diferentes tratamentos pré-germinativos.

Figure 5-Length of aerial part of Parkia platycephala seedlings originated from seeds submitted to different pregermination treatments.
Quando as sementes foram submetidas à escarificação mecânica com lixa $\left(\mathrm{T}_{2}\right)$, elas originaram plântulas com maior massa seca das raízes (Figura 6), enquanto os demais tratamentos se mostraram ineficientes em promover aumentos dessa variável. Quanto à massa seca da parte aérea (Figura 7), os maiores valores foram registrados nas plântulas oriundas de sementes submetidas ao tratamento de imersão em ácido sulfúrico concentrado por 30 e $45 \min \left(\mathrm{T}_{11}\right.$ e $\mathrm{T}_{10}$, respectivamente).

Sementes de Mimosa caesalpiniaefolia submetidas a tratamentos pré-germinativos com ácido sulfúrico concentrado por 10 ou 13 min originaram plântulas com maior conteúdo de massa seca (BRUNO et al., 2001). Também, Sampaio et al. (2001) verificaram maior conteúdo de massa em plântulas de Bowdichia virgilioides com a imersão das sementes em ácido sulfúrico concentrado por períodos entre 8 e $11 \mathrm{~min}$.

Os tratamentos de superação da dormência (escarificação mecânica em escarificador elétrico da marca Forsberg 1725 RPM por 15 seg; imersão em água quente a $90^{\circ} \mathrm{C}$ e imersão em água quente em início de ebulição $97^{\circ} \mathrm{C}$ ) utilizados em sementes de Acacia mearnsi Willd. diferiram apenas da testemunha (sementes intactas) (ROVERSI et al., 2002).

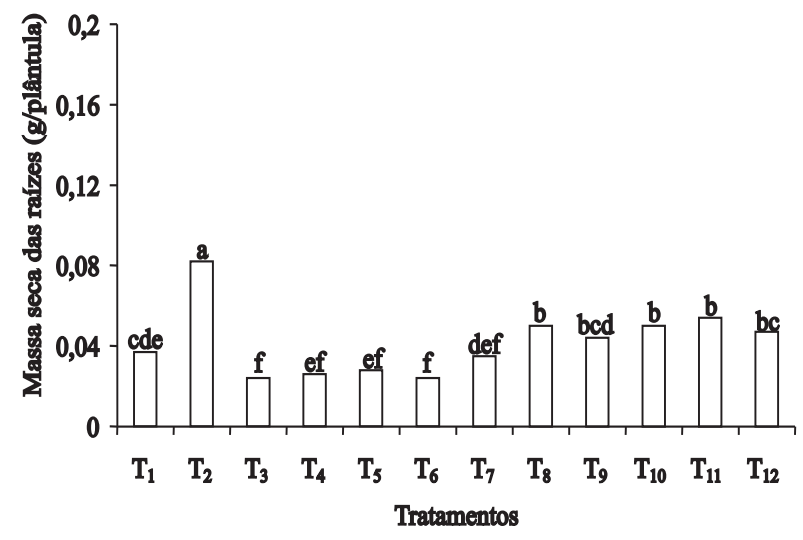

Médias seguidas de mesma letra não diferem estatisticamente, pelo teste de Tukey a $5 \%$.

Testemunha $\left(\mathrm{T}_{1}\right)$ - sementes intactas; escarificação mecânica com lixa d'água n. $80\left(\mathrm{~T}_{2}\right)$; imersão em ácido muriático concentrado (98\%) por 30 min e $1 \mathrm{~h}\left(\mathrm{~T}_{3}^{2} \mathrm{e} \mathrm{T}_{4}\right.$, respectivamente); escarificação mecânica com brita por 5,10 e 15 min $\left(\mathrm{T}_{5}, \mathrm{~T}_{6}\right.$ e $\mathrm{T}_{7}$, respectivamente); e imersão em ácido sulfúrico concentrado $(98 \%)$ por 5, 15, 30, 45 e $60 \mathrm{~min}$ $\left(\mathrm{T}_{8}, \mathrm{~T}_{9}, \mathrm{~T}_{10}, \mathrm{~T}_{11}\right.$ e $\mathrm{T}_{12}$, respectivamente).

Figura 6 - Massa seca das raízes de plântulas de Parkia platycephala oriundas de sementes submetidas a diferentes tratamentos pré-germinativos.

Figure 6-Root dry mass of Parkia platycephala seedlings originated from seeds submitted to different pregermination treatments.

R. Árvore, Viçosa-MG, v.33, n.1, p.35-45, 2009 


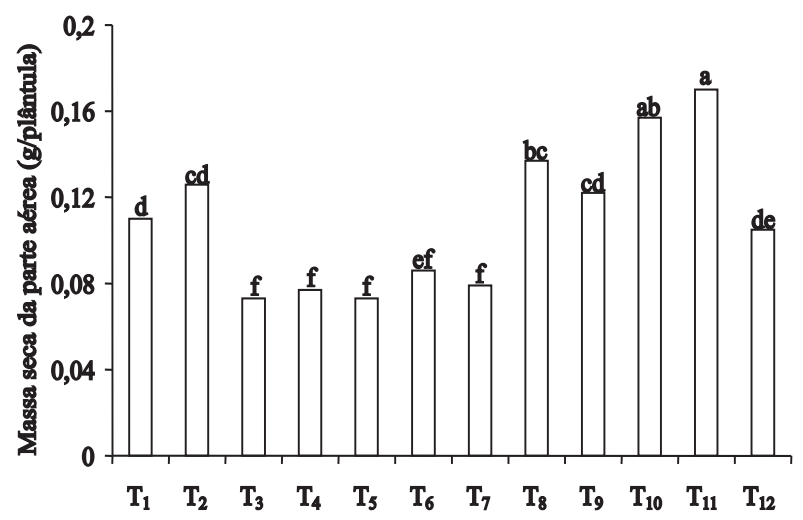

Médias seguidas de mesma letra não diferem estatisticamente, pelo teste de Tukey a $5 \%$.

Testemunha $\left(\mathrm{T}_{1}\right)$ - sementes intactas; escarificação mecânica com lixa d'água n. $80\left(\mathrm{~T}_{2}\right)$; e imersão em ácido muriático concentrado $(98 \%)$ por 30 min e $1 \mathrm{~h}$ ( $\mathrm{T}_{3}$ e $\mathrm{T}_{4}$, respectivamente); escarificação mecânica com brita por 5,10 e 15 min ( $\mathrm{T}, \mathrm{T}$ e $\mathrm{T}$, respectivamente); e imersão em ácido sulfúrico concentrado $(98 \%)$ por $5,15,30,45$ e $60 \mathrm{~min}$ $\left(\mathrm{T}_{8}, \mathrm{~T}_{9}, \mathrm{~T}_{10}, \mathrm{~T}_{11}\right.$ e $\mathrm{T}_{12}$, respectivamente).

Figura 7 - Massa seca da parte aérea de plântulas de Parkia platycephala oriundas de sementes submetidas a diferentes tratamentos pré-germinativos.

Figure 7 - Dry mass of the aerial part of Parkia platycephala seedlings originated from seeds submitted to different pre-germination treatments.

Sementes de Sterculia foetida submetidas à escarificação em um lado, seguida de embebição, originaram plântulas com maior massa seca da parte aérea, enquanto na massa seca do sistema radicular não houve diferença significativa entre os tratamentos (SANTOS et al., 2004).

Em Bauhinia divaricata, os maiores valores de massa seca das plântulas foram obtidos com sementes submetidas aos tratamentos de desponte na região oposta a micrópila e imersão em água na temperatura de $70^{\circ} \mathrm{C}$; no entanto, não diferiu estatisticamente da massa seca das plântulas submetidas aos tratamentos de imersão em águas na temperatura de $60^{\circ} \mathrm{C}$ (ALVES et al., 2004). No entanto, para Zizyphus joazeiro o pré-condicionamento das unidades de dispersão em ácido sulfúrico concentrado mostrouse eficiente, pois promoveu aumento na massa seca das plantas (ALVES et al., 2006).

\section{CONCLUSÃO}

Os tratamentos de escarificação mecânica com lixa e química com ácido sulfúrico (98\% p.a.) por períodos entre 15 e $45 \mathrm{~min}$ foram eficientes para superar a impermeabilidade à água do tegumento das sementes de Parkia platycephala.
A impermeabilidade do tegumento das sementes de Parkia platycephala não foi superada com ácido muriático nas concentrações utilizadas.

\section{REFERÊNCIAS}

ALVES, A. A. et al. Degradabilidade ruminal in situ de vagens de faveira (Parkia platycephala Benth.) em diferentes tamanhos de partículas. Arquivo Brasileiro de Medicina Veterinária e Zootecnia, v.59, n.4, p.1045-1051, 2007.

ALVES, E. U. et al. Ácido sulfúrico na superação da dormência de unidades de dispersão de juazeiro (Zizyphus joazeiro Mart.). Revista Árvore, v.30, n.2, p.187-195, 2006.

ALVES, M. C. S. et al. Superação de dormência em sementes de Bauhinia monandra Britt. e Bauhinia ungulata L.Cesalpinoideae. Revista Brasileira de Sementes, v.22, n.2, p.139-144, 2000.

ALVES, A. U. et al. Superação da dormência em sementes de Bauhinia divaricata L. Acta Botânica Brasílica, v.18, n.4, p.871-879, 2004.

ARAÚJO-NETO, J. C.; AGUIAR, I. B. Tratamentos pré-germinativos para superar a dormência de sementes de Guazuma ulmifolia Lam. Scientia Forestalis, n.58, p.15-24, 2000.

BARBOSA, A. P. et al. Tecnologia alternativa para a quebra de dormência das sementes de pau-debalsa (Ochroma lagopus Sw., Bombacaceae).

Acta Amazônica, v.34, n.1, p.107-110, 2004.

BERTALOT, M. J.; NAKAGAWA, J. Superação da dormência em sementes de Leucaena diversifolia (Schlecht.) Bentham K 156. Revista Brasileira de Sementes, v.20, n.1, p.39-42, 1998.

BEWLEY, J. D.; BLACK, M. Seeds physiology of development and germination. New York: Plenum, 1985.367p.

BEWLEY, J. D.; BLACK, M. Seeds: physiology of development and germination. 2.ed. New York: Plenum Press, 1994. 445p. 
BIANCHETTI, A.; TEIXEIRA, C. A. D.; MARTINS, E. P. Escarificação ácida para superar a dormência de sementes de pinho cuiabano (Parkia multijuga Benth.). Revista Brasileira de Sementes, v.20, n.1, p.215-218, 1998.

BORGES, E. E. L. et al. Alterações fisiológicas em sementes de Tachigalia multijuga (Benth.) (mamoneira) relacionadas aos métodos para a superação da dormência. Revista Árvore, v.28, p.317-325, 2004.

BOSCAGLI, A.; SETTE, B. Seed germination enhacement in Satureja Montana L. spp. Montana. Seed Science and Technology, v.29, n.2, p.347-355, 2001.

BRASIL. Ministério da Agricultura e da Reforma Agrária. Regras para análise de sementes. Brasília: SNDA/DNDV/CLAV, 1992.365p.

BRUNO, R. L. A. et al. Tratamentos prégerminativos para superar a dormência de sementes de Mimosa caesalpiniaefolia Benth.

Revista Brasileira de Sementes, v.23, n.2, p.136-143, 2001.

CARVAlho, N. M.; NAKAGAWA, J. Sementes: ciência, tecnologia e produção. 4.ed Jaboticabal: FUNEP, 2000. 429p.

CASTELlANI, E. D.; AGUIAR, I B. Efeito da escarificação na germinação de sementes de candiúba (Trema micrantha (L.) Blume).

Revista Brasileira de Sementes, v.19, n.2, p.384-388, 1997.

CRUZ. E. D.; CARVALHO, J. E. U.; LEÃO, N. V. M. Métodos para superar dormência e biometria de frutos e sementes de Parkia nitida Miquel. (Leguminosae-Mimosoideae). Acta Amazônica, v.31, n.2, p.167-177, 2001.

DEMINICIS, B. B. et al. Superação da dormência de sementes de oito leguminosas forrageiras tropicais. Archivos de Zootecnia, v.55, n.212, p.401-404, 2006.

ESCHIAPATI-FERREIRA, M. S.; PEREZ, S. C. J. G. A. Tratamentos para superar a dormência de sementes de Senna macranthera. Revista Brasileira de Sementes, v.19, n.2, p.231-237, 1997.
FERNANDEZ, C. D.; GROF, B.; CARVALHO, J. Escarificação mecânica de sementes de Stylosanthes spp. com beneficiadora de arroz. Embrapa, 2000. 4p. (Comunicado Técnico).

FRANKE, L. B.; BASSEGIO, J. Superação da dormência de sementes de Desmodium incanum DC. e Lathyrus nervosus Lam. Revista Brasileira de Sementes, v.20, n.2, p.420-424, 1998.

GARCIA, J.; DUARTE, J. B.; FRASSETO, E. G. Superação de dormência em sementes de sansãodo-campo (Mimosa caesalpiniaefolia L.).

Pesquisa Agropecuária Tropical, v.32, n.1, p.29-31, 2002.

HERMANSEN, L. A. et al. Pretreatments to overcome seed coat dormancy in Dimorphandra mollis Benth. Seed Science and

Technology, v.28, n.3, p.581-595, 2000.

HOPKINS, H. C. F. Parkia (Leguminosae: Mimosoideae). In: HOPKINS, H. C. F. Flora Neotrópica. New York: The New York Botanical Garden, 1986. 44p.

INSTITUTO BRASILEIRO DE DESENVOLVIMENTO FLORESTAL - IBDF. Padronização da nomenclatura comercial brasileira das madeiras tropicais amazônicas. Brasília: 1987. 85p.

JELLER, H.; PEREZ, S. C. J. G. A. Estudo da superação da dormência e da temperatura em sementes de Cassia excelsa Schrad. Revista Brasileira de Sementes, v.21, p.32-40, 1999.

LOPES, J. C.; DIAS, P. C.; MACEDO, C. M. P. Tratamentos para acelerar a germinação e reduzir a deterioração das sementes de Ormosia nitida Vog. Revista Árvore, v.30, n.2, p.171-177, 2006.

LOPES, J. C.; DIAS, P. C.; MACEDO, C. M. P. Tratamentos para superar a dormência de sementes de Ormosia arborea (Vell.) Harms. Brasil Florestal, n.80, p.25-35, 2004.

R. Árvore, Viçosa-MG, v.33, n.1, p.35-45, 2009 
LOPES, C. L. et al. Germinação de sementes de espécies florestais de Caesalpinia ferrea Mart.ex Tul. var. leiostachya Benth., Cassia grandis L. e Samanea saman Merrill, após tratamentos para superar a dormência. Revista Brasileira de Sementes, v.20, n.1, p.80-86, 1998.

LORENZI, H. Árvores brasileiras: manual de identificação e cultivo de plantas arbóreas do Brasil. 4.ed. Nova Odessa: Instituto Plantarum, 2002. v.2.368p.

MAGUIRE, J. D. Speed of germination-aid in selection and evaluation for seedling emergence and vigor. Crop Science, v.2, n.2, p.176-177, 1962 .

MAYER, A. M.; POLJAKOFF-MAYBER, A. The germination of seeds. 3.ed. New York: Pergamon, 1982. 211p.

MEDEIROS FILHO, S.; FRANÇA, E. A.; INNECCO, R. Germinação de sementes de Operculina macrocarpa (L.) Farwel e Operculina alata (Ham.) Urban. Revista Brasileira de Sementes, v.24, n.2, p.102-107, 2002.

MEDEIROS, R. B.; NABINGER, C. Superação da dormência em sementes de leguminosas forrageiras. Revista Brasileira de Sementes. v.18, n.2, p.193-199, 1996.

MENEGHELLO, G. E. et al. Tratamentos para superar a dormência de sementes de Enterolobium contortisiliquum (Vell.) Morong. Agropecuária de Clima Temperado, v.3, n.2, p.199-204, 2000.

MONTEIRO, P. P. M.; RAMOS, F. A.

Beneficiamento e quebra de dormência de sementes de cinco espécies florestais do cerrado. Revista Árvore, v.21, n.2, p.169-174, 1997.

NAKAGAWA, J. Testes de vigor baseados no desempenho das plântulas. In: KRZYZANOWSKI, F. C.; VIEIRA, R.D.; FRANÇA NETO, J. B. Vigor de sementes: conceitos e testes. Londrina: ABRATES, 1999. p.2-15.

ODOEMENA, C. S. Breaking of seed coat dormancy in a medicinal plant Tetrapleura tetraptera (Schum \& Thonn). Journal of Agricultural Science, v.111, n.2, p.393-394, 1988.

R. Árvore, Viçosa-MG, v.33, n.1, p.35-45, 2009
OLIVEIRA, L. M.; DAVIDE,A. C.; CARVALHO, M. L. M. Avaliação de métodos para quebra da dormência e para a desinfestação de sementes de canafístula (Peltophorum dubium (Sprengel) Taubert). Revista Árvore, v.27, n.5, p.597-603, 2003.

PEREZ, S. C. J. G. A. Envoltórios. In: FERREIRA, A. G.; BORGHETTI, F. Germinação: do básico ao aplicado. Porto Alegre: Artmed, 2004. p.125-134.

PEREZ, S. C. J. G. A.; FANTI, S. C.; CASALI, C. A. Dormancy break and light quality effects on seed germination of Peltophorum dubium Taub. Revista Árvore, v.23, n.2, p.131-137, 1999.

POPINIGIS, F. Fisiologia da semente. Brasília: AGIPLAN, 1985. 289p.

PRASAD, P.; NAUTIYAL, A. R. Physiology of germination in Bauhinia: involvement of seed coat inhibition of germination in B. racemosa seeds. Seed Science and Technology, v.24, n.2, p.305-308, 1996.

ROLSTON, M. P. Water impermeable seed dormancy. The Botanical Review, v.44, n.3, p.365-396, 1978 .

ROVERSI, T. et al. Superação da dormência em sementes de acácia negra (Acacia mearnsii Willd.). Revista Brasileira de Agrociência, v.8, n.2, p.161-163, 2002.

SAMPAIO, L.S.V. et al. Ácido sulfúrico na superação da dormência de sementes de sucupirapreta (Bowdichia virgilioides H.B.K. - Fabaceae). Revista Brasileira de Sementes, v.23, n.1, p.184-190, 2001.

SANTOS, T. O.; MORAIS, T. G. O.; MATOS, V. P. Escarificação mecânica em sementes de chichá (Sterculia foetida L.). Revista Árvore, v.28, n.1, p.1-6, 2004.

SMIDERLE, O. J.; MOURÃO JUNIOR, M.; SOUSA, R. C. P. Tratamentos pré-germinativos em sementes de acácia. Revista Brasileira de Sementes, v.27, n.1, p.78-85, 2005.

SMIDERLE, O. J.; SOUSA, R. C. P. Dormência em sementes de paricarana (Bowdichia virgilioides Kunth - Fabaceae - Papilionidae). Revista Brasileira de Sementes, v.25, n.2, p.48-52, 2003. 
SREERAMA, R. et al. Effect of pre-sowing treatments on seed germination of ornamental trees. Current Research, v.29, n.7-8, p.127-128, 2000.

SUÑÉ, A. D.; FRANKE, L. B. Superação de dormência e metodologias para testes de germinação em sementes de Trifolium riograndense Burkart e Desmanthus depressus Humb. Revista Brasileira de Sementes, v.28, n.3, p.29-36, 2006.

TELES, M. M. et al. Métodos para quebra da dormência em sementes de leucena (Leucaena leucocephala (Lam.) de Wit. Revista

Brasileira de Zootecnia, v.29, n.2, p.387-391, 2000 .
VARELA, V. P.; AQUINO, P. A. N.; AZEVEDO, C. $P$. Tratamentos pré-germinativos em sementes de espécies florestais da Amazônia. III. Faveiraarara-tucupi (Parkia decussata Ducke) Leguminoseae. Acta Amazônica, v.16, n.17, p.557-562, 1986/1987.

VILLIERS, T. A. Seed dormancy. In: KOZLOWSKY, T. T. (Ed). Seed biology. v.2. New York: Academic Press, 1972. p.220-282.

YAP, S. K.; WONG, S. M. Seed biology of Acacia mangium, Albizia falcataria, Eucalyptus spp., Gmelina arborea, Masopsis eminiis, Pinus caribaea and Tectonia grandis. The

Malaysian Forester, v.6, n.1, p.26-45, 1983. 